\title{
REKAYASA ALAT PENGERING JAGUNG SISTEM ROTARY
}

\section{DESIGN OF MULTIPURPOSE DRYER USING ROTARY SYSTEM}

\author{
Nicolas Tumbel, Broerie Pojoh dan Supardi Manurung \\ Balai Riset dan Standardisasi Industri Manado \\ Jalan Diponegoro No: 21-22 Manado \\ Pos-el: nicolastumbel@yahoo.co.id \\ Diterima tgl 20-07-2016, Disetujui tgl 15-08-2016
}

\begin{abstract}
ABSTRAK
Prinsip kerja pengering rotary dryer adalah menggunakan panas yang dialirkan secara langsung dengan bahan yang akan dikeringkan melalui drum yang berputar. Sumber panas yang digunakan berasal dari api gas LPG yang bersentuhan dengan permukaan drum pengering. Suhu pemanasan dapat diatur secara manual dengan menyetel gas yang keluar dari tabung gas. Sistem rotari digunakan agar pengeringan bersifat merata. Alat pengering yang dirancang secara keseluruhan memiliki panjang $220 \mathrm{~cm}$, lebar $62 \mathrm{~cm}$ dan tinggi $50 \mathrm{~cm}$. Alat digerakkan menggunakan motor listrik. Komponen alat meliputi drum pengering, termometer, motor listrik $1 \mathrm{HP} / 1420 \mathrm{rpm}$ dengan reducer 50:1, dan gas LPG. Alat pengering diuji untuk mengeringkan jagung sebanyak $50 \mathrm{~kg}$, pada suhu pengeringan sekitar $70-75^{\circ} \mathrm{C}$ dengan lama pengeringan 10 jam. Hasilnya adalah kadar air jagung turun dari 30,37\% menjadi 16,13\%, tidak terdapat kerusakan pada jagung seperti butir pecah ataupun perubahan warna. Sementara dalam proses ada kehilangan hasil sebesar $1 \%$ yang disebabkan tertinggalnya bahan di dalam alat.
\end{abstract}

Kata kunci : alat pengering, rotary dryer, jagung

\section{ABSTRACT}

The working principle of rotary dryer is distribution heat directly to the material to be dried through a rotating drum. The heat source is derived from LPG gas flame in contact with the surface of the dryer drum. The heating temperature can be set manually by adjusting the gas out of the gas tube. Rotary drying system is used in order to even the drying. Dryer that designed has a length of $220 \mathrm{~cm}$, width of 62 $\mathrm{cm}$ and height of $50 \mathrm{~cm}$. This equipment is driven using electric motors. The components consist of drum dryers, thermometer, electric motor $1 \mathrm{Hp} / 1420 \mathrm{rpm}$ with a reducer 50:1, and LPG gas. The dryer was tested for drying corn as much as $50 \mathrm{~kg}$, the drying temperature around $70-75^{\circ} \mathrm{C}$ with long drying time of 10 hours. The result is the moisture content of corn decrease from $30.37 \%$ to $16.13 \%$, with no damage to corn as grain rupture or discoloration. While in the process there is a loss of yield by $1 \%$ due to lagging material within the device.

Keywords: dryer, rotary dryer, corn

\section{PENDAHULUAN}

Teknik pengolahan pangan cukup beragam mulai dari cara yang sederhana, seperti penjemuran sampai yang canggih dengan memerlukan peralatan yang rumit dan tenaga khusus yang terlatih. Pengetahuan dasar tentang metode pengawetan pangan, baik yang tradisional yang telah bertahan sepanjang masa maupun yang merupakan hasil ilmu pengetahuan modern, akan membantu pemahaman tentang kedudukan iradiasi pangan diantara berbagai metode tersebut (1).

Pengeringan memberikan manfaat lain yang penting selain melindungi pangan yang mudah rusak. Pengurangan air menurunkan bobot dan memperkecil volume pangan sehingga mengurangi biaya pengangkutan dan penyimpanan. Pengeringan juga memudahkan penanganan, pengemasan, pengangkutan dan konsumsi (2).

Sekarang ini kemajuan teknologi
pascapanen di Indonesia menuntut
tersedianya bahan baku yang bermutu


tinggi untuk industri pengolahan hasil pertanian. Produk-produk pertanian yang berbentuk butiran, seperti jagung, padi, kacang-kacangan, kopi dan lain-lain memerlukan perhatian yang lebih serius, terutama pada proses pengawetan. Proses pengeringan memegang peranan penting dalam pengawetan suatu bahan. Proses pengeringan juga membantu mempermudah penyimpanan produk pertanian dalam rangka pendistribusian baik dalam skala domestik maupun ekspor. Proses pengeringan butiran bertujuan untuk mengurangi kandungan airnya sampai batas-batas tertentu, agar tidak terjadi kerusakan akibat aktivitas metabolisme oleh mikroorganisme (3).

Di Indonesia, pengeringan butiran pada umumnya masih dilakukan dengan memanfaatkan tenaga matahari. Namun, cara ini sangat tergantung pada musim, waktu pengeringan, tenaga kerja yang banyak, dan tempat yang luas. Pengeringan butiran yang berkadar air tinggi, dapat dilakukan dengan dua cara, yaitu pengeringan dalam jangka waktu lama pada suhu udara pengering yang rendah atau pengeringan dalam jangka waktu yang lebih pendek pada suhu yang lebih tinggi. Akan tetapi, jika pengeringan dilakukan terhadap suatu bahan berlangsung terlalu lama pada suhu yang rendah, maka aktivitas mikroorganisme yang berupa tumbuhnya jamur atau pembusukan menjadi sangat cepat. Sebaliknya, pengeringan yang dilakukan pada suhu yang terlalu tinggi dapat menyebabkan kerusakan pada komponen-komponen bahan yang dikeringkan, baik secara fisik maupun kimia. Oleh karena itu, perlu dipilih cara pengeringan yang efektif dan efisien agar tidak terjadi kerusakan pada produk-produk pertanian (4).

Di Indonesia, pengeringan biji-bijian dengan menggunakan alat pengering belum lazim digunakan. Kalaupun ada, masih sangat terbatas penggunaannya. Metode pengeringan buatan yang telah dikembangkan dan diujicobakan antara lain adalah alat pengering surya (solar dryer), alat pengering tungku dan alat pengering tenaga listrik. Beberapa jenis alat pengering yang dapat digunakan antara lain adalah : Flat Bed-type Dryer, Upright-Type Forced Air Dryer, Circulation Dryer, dan Continuous Flow Dryer.

Penggunaan alat pengering buatan adalah untuk menghindari kelemahankelemahan yang diakibatkan oleh metode pengeringan alami (penjemuran). Pada dasarnya, metode pengeringan buatan dilakukan melalui pemberian panas yang relatif konstan terhadap bahan biji-bijian, sehingga proses pengeringan dapat berlangsung dengan cepat dengan hasil yang maksimal. Dengan pengeringan buatan diharapkan kandungan air mulamula sekitar $30-50 \%$ akan turun sedemikian rupa hingga mencapai kadar air $12-17 \%$. Pada kadar air tersebut, biji-bijian telah cukup siap untuk pengolahan lebih lanjut (penggilingan) ataupun telah cukup aman dalam penyimpanan (5).

Pengeringan dengan konveksi untuk bahan padat (seperti biji-bijian hasil pertanian) di bagi dalam dua periode, yaitu periode pertama dengan kecepatan pengeringan tetap, yaitu pada saat air yang terdapat pada permukaan teruapkan. Pada periode ini kecepatan pengeringan 
dipengaruhi oleh suhu kelembaban udara dan kecepatan aliran udara serta kecepatan sirkulasi dan periode kedua dengan kecepatan pengeringan semakin menurun (2).

Proses pengeringan terjadi melalui penguapan air karena perbedaan tekanan dan potensial uap air antara udara dengan bahan yang dikeringkan. Penguapan kandungan air yang terdapat dalam bahan juga terjadi karena adanya panas yang dibawa oleh media pengering yaitu udara. Uap air tersebut akan dilepaskan dari permukaan bahan ke udara pengering. Penguapan air dari bahan meliputi empat tahap yaitu: 1) Pelepasan ikatan dari bahan, 2) Difusi air dan uap air ke permukaan bahan, 3) Perubahan tahap menjadi uap air, 4) Perpindahan uap air ke udara (3). Penurunan kadar air dari $30-50 \%$ pada bijibijian tidak mungkin dilakukan dengan matahari dalam beberapa jam, walaupun dengan panas matahari terus-menerus. Penelitian ini bertujuan untuk menguji kinerja alat mesin pengering sistem "rotary dryer" pada biji jagung.

\section{METODOLOGI}

\section{Bahan dan Peralatan}

Bahan utama yang dipakai adalah plat stainless steel, besi baja, reducer/gear box, gurinda, mur, baut, cat minyak dan biji jagung (Zea mays) yang sudah dikupas diperoleh dari Remboken, Kecamatan Kakas, Kabupaten Minahasa untuk ujicoba alat. Peralatan yang digunakan adalah alat pemotong besi/baja, alat pengelas listrik, kompor, gas LPG, termometer $100^{\circ} \mathrm{C}$, stop watch, timbangan dan kabel rol.

\section{Metode Penelitian}

Penelitian ini dilaksanakan dengan membuat rancangan alat pengering yang akan dibuat, kemudian dilakukan pembuatan alat manual dengan skala yang kecil. Uji coba manual dilakukan untuk mengetahui putaran (rpm) yang dibutuhkan. Setelah itu alat dirancang dengan skala yang lebih besar. Kemudian dilakukan ujicoba dengan menggunakan jagung. Percobaan ini dilakukan sebanyak 2 kali. Hasil percobaan diuji berdasarkan Standar Mutu Jagung berdasarkan SNI 01-39201995. Metode data pengamatan yang diperoleh dianalisis secara deskriptif. Diagram alir proses pembuatan dan ujicoba alat disajikan pada Gambar 1.

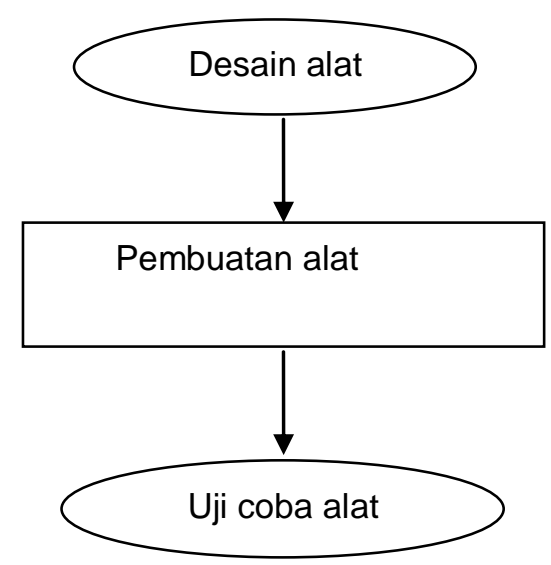

Gambar 1. Diagram alir proses pembuatan dan uji coba alat.

\section{Uji Kinerja Alat}

Uji kinerja alat dilihat berdasarkan kapasitas alat, kadar air bahan, butir yang rusak, butir warna lain, butir pecah dan kemungkinan adanya kotoran. Metode yang digunakan adalah dengan gravimetri.

HASIL DAN PEMBAHASAN 


\section{A. Rancangan Alat pengering}

Hasil rancangan alat pengering sistem "rotary dryer" memiliki dimensi panjang 220 $\mathrm{cm}$, lebar $62 \mathrm{~cm}$ dan tinggi $50 \mathrm{~cm}$. Alat pengering rotary hasil rancangan menunjukkan bahwa kondisi fisik dari masing-masing unit proses dapat beroperasi secara normal. Kegiatan percobaan alat pengering pada biji jagung dengan rata-rata berat $50 \mathrm{~kg}$ dengan diawali suhu dalam drum pengering sekitar $30-32^{\circ} \mathrm{C}$, pada kadar air awal jagung 30,37\% dan suhu di dalam drum pengering selama pengeringan berkisar $70-75^{\circ} \mathrm{C}$. Alat tersebut terdiri dari beberapa bagian/komponen sebagaimana ditunjukkan dalam Gambar 2 berikut ini :

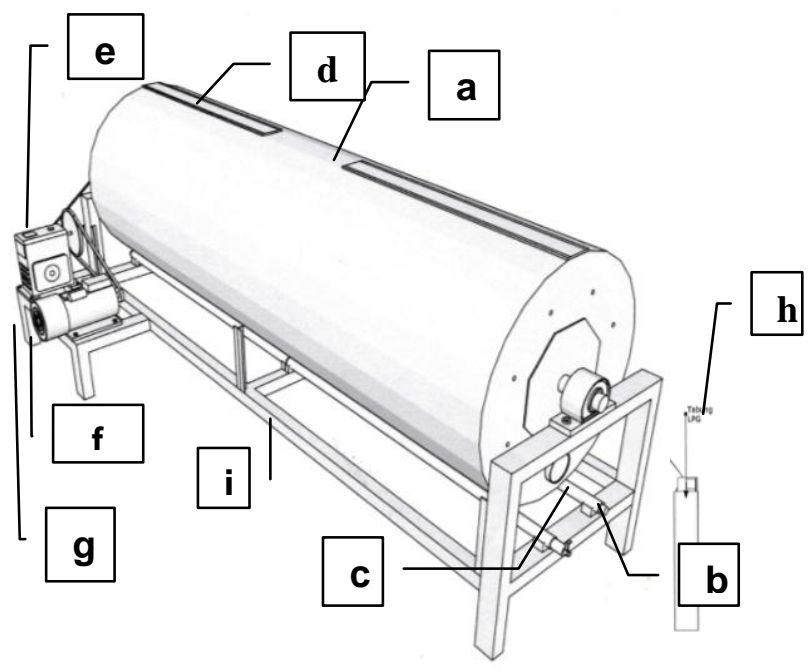

\section{Gambar 2. Alat pengering system rotary dryer}

Keterangan :
a) Drum Pengering
b) Pipa Gas
c) Thermometer
d) Tempat Masuk \& Keluar Bahan
e) Saklar Listrik (on/off)
f) Elektro Motor
g) Reducer/gear box
h) Pemanas LPG
i) Kerangka Dudukan

Secara fungsional rancangan alat pengering rotary dryer terdiri atas beberapa komponen dan bagian dengan fungsi-fungsi tertentu, antara lain drum pengering, pipa pemanas, termometer, tempat pemasukan dan pengeluaran bahan, pemanas bahan bakar LPG, motor listrik (handle On/Off) dan reducer/gear box, tempat penampung produk, dan dudukan kerangka alat.

Drum pengering (tabung silinder pengering) berfungsi untuk menempatkan produk pertanian (biji-bijian). Drum pengering produk pertanian dengan panjang $200 \mathrm{~cm}$ diameter $60 \mathrm{~cm}$ terbuat dari plat stainless steel (SS) 2,0 mm, dilengkapi dengan termometer $100^{\circ} \mathrm{C}$, tempat masuk dan keluar produk bahan berukuran 10x68 $\mathrm{cm}$, terdapat as/poros di dalam drum pengering terbuat dari besi baja ukuran diameter 1,5 inci.

- Pipa gas pembakaran berfungsi untuk memanaskan drum pengering dan tempat keluarnya nyala api. Terbuat dari besi galvanist berbentuk pipa. Pipa pemanas drum terdiri dari 2 (dua) jalur, terbuat dari besi galvanist ukuran 1/2 inci dengan panjang $220 \mathrm{~cm}$. Pipa ini akan menghasilkan nyala api yang tersambung dan berasal dari kompor pemanas gas LPG. Lihat Gambar 3. Alat pengering tampak kanan dan tampak kiri.

- Tempat lubang pemasukan/ pengeluaran bahan berfungsi sebagai tempat masuk dan keluarnya bahan sebelum dan sesudah proses. Tempat pemasukan/pengeluaran bahan terdiri dari dua buah lubang terbuat dari plat SS $2 \mathrm{~mm}$ dengan ukuran panjang $68 \mathrm{~cm}$ lebar $10 \mathrm{~cm}$. 
- Panel listrik berfungsi untuk menghentikan/mengaktifkan (saklar on/off) aliran listrik. Panel listrik (saklar on/off) dengan kabel listrik tersambung dengan motor listrik/reducer.

- Motor listrik dan reducer speed/gear box (transmisi) berfungsi untuk memutar drum pengering. Reducer adalah alat yang berfungsi untuk mentransmisikan putaran tinggi menjadi putaran rendah, sehingga motor yang memiliki putaran tinggi diubah menjadi pelan oleh reducer. Reducer untuk memperlambat kecepatan yang berasal dari motor listrik. Motor listrik ukuran $1 \mathrm{HP} 1420 \mathrm{rpm}$, reducer 50 : 1, pulley dan sabuk. Lihat gambar 3 . Alat pengering tampak kanan dan tampak kiri.

- Nampan hasil produk berfungsi sebagai tempat tampung dan jatuhnya hasil produk dari drum pengering. Nampan hasil produk terbuat dari seng plat dengan ukuran panjang $80 \times 50 \times 10 \mathrm{~cm}$.

- Kompor pemanas bahan bakar LPG berfungsi sebagai sumber panas pada proses pengeringan.

- Thermometer $\left(100^{\circ} \mathrm{C}\right)$ berfungsi melihat suhu dalam drum pengering.

- Kerangka dudukan berfungsi sebagai tempat melekatnya seluruh bagian komponen unit-unit pengeringan dengan konstruksi pada bagian ini harus kuat dan tahan goyangan atau getaran pada waktu operasional. Kerangka/dudukan alat pengering rotary terbuat dari besi $U$ $6,5 \times 0,5 \mathrm{~cm}$ dengan ukuran panjang 220 $\mathrm{cm}$ lebar $62 \mathrm{~cm}$ dan tinggi $50 \mathrm{~cm}$. Kerangka ini harus kuat, kokoh dan tahan goyangan.
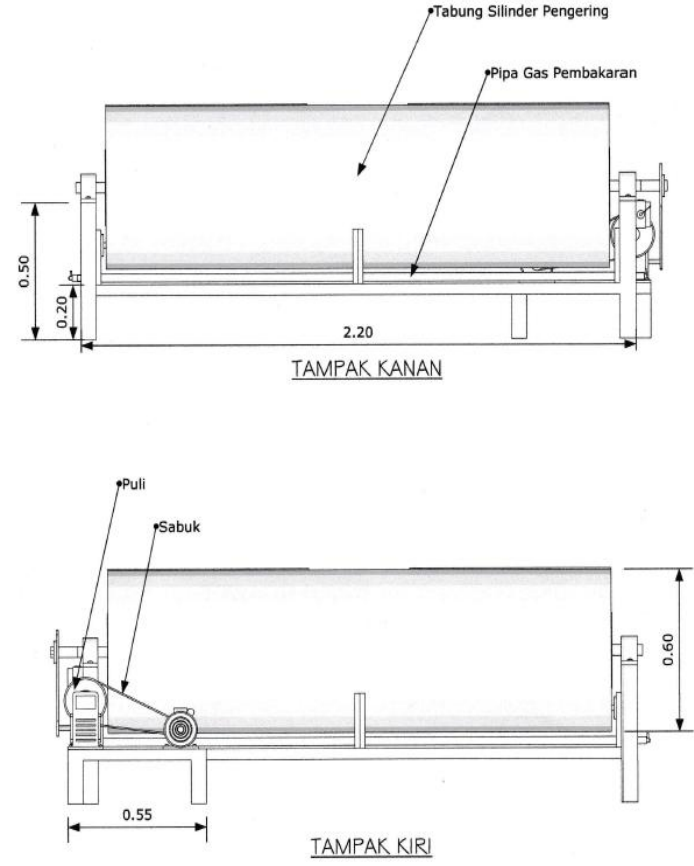

Gambar 3. Alat pengering tampak kanan dan tampak kiri.

\section{B. Uji Kinerja Alat}

1. Kapasitas alat

Tabel 1. Kapasitas hasil percobaan

\begin{tabular}{ccc}
\hline Ulangan & $\begin{array}{c}\text { Berat biji jagung } \\
(\mathbf{K g})\end{array}$ & $\begin{array}{c}\text { Waktu } \\
\text { pengeringan } \\
\text { (jam) }\end{array}$ \\
\hline I & 50 & 10 \\
II & 50 & 10 \\
Rata-rata & 50 & 10 \\
\hline
\end{tabular}

Pada Tabel 1, dapat dilihat bahwa kapasitas percobaan alat pengering dengan berat biji jagung $50 \mathrm{~kg}$ dikeringkan selama 10 jam. Kapasitas kerja alat pengering ini dapat ditingkatkan bila berat biji jagung ditambahkan.

Kapasitas kerja alat tergantung pada daya motor dan reducer serta pulley/belt yang digunakan (6). Kapasitas kerja dapat dinaikkan bila besaran/laju putaran per menit ditingkatkan, karena menurut hasil penelitian dinyatakan bahwa besaran daya 
dapat berpengaruh terhadap waktu proses pengolahan dan kapasitas alat pengolahan. Selain itu biji jagung dapat ditambahkan lagi jika dilihat dari panjang dan diameter drum dan ini diperlukan keahlian operator dalam mengoperasi alat ini.

\section{Rendemen}

Tabel 2. Rendemen

\begin{tabular}{cccc}
\hline Ulangan & $\begin{array}{l}\text { Berat biji } \\
\text { jagung } \\
(\mathbf{K g})\end{array}$ & $\begin{array}{c}\text { Jagung } \\
\text { kering } \\
(\mathbf{K g})\end{array}$ & $\begin{array}{c}\text { Rende } \\
\text { men } \\
(\%)\end{array}$ \\
\hline I & 50 & 40 & 80 \\
II & 50 & 42 & 84 \\
$\begin{array}{c}\text { Rata- } \\
\text { rata }\end{array}$ & 50 & 41 & 82 \\
\hline
\end{tabular}

Pada Tabel 2, dapat dilihat bahwa rendemen hasil yang diperoleh rata-rata adalah $82 \%$. Ini diperoleh dari hasil bagi antara berat biji jagung kering dengan produk jagung awal.

Hasil rendemen $82 \%$ alat pengering ini masih terlalu tinggi, hal ini mungkin disebabkan masih banyaknya kandungan air yang terkandung dalam biji jagung. Selain itu rendemen pada mutu jagung dipengaruhi oleh bahan baku (kondisi tanaman, umur panen), penanganan pasca panen (pengeringan dan penyimpanan) dan proses ekstraksi (perajangan, lama perebusan) (7).

1. Kehilangan hasil

Pada Tabel 3, dapat dilihat bahwa persentase kehilangan hasil biji jagung pada alat pengering rotary sekitar 1,0\%. Kehilangan hasil yang diperoleh hanya $1,0 \%$, dibandingkan dengan pengolahan tradisional petani (dijemur dengan parapara) dengan tingkat kehilangan hasil mencapai 3-5\% (8). Kehilangan hasil terjadi pada biji jagung yang keluar pada lubanglubang drum pengering disisi kiri dan kanan yaitu lubang uap panas, kemudian biji jagung masih ada yang tertinggal didalam drum pengering. Kehilangan hasil dapat terjadi jika operator belum ahli atau kurang berpengalaman dalam mengoperasikan alat pengering rotary. Selain itu pada proses pengering yang sedang berlangsung perlu ketelitian dan kesabaran bagi operator.

Tabel 3. Persentase kehilangan hasil

\begin{tabular}{ccccc}
\hline Ulangan & $\begin{array}{c}\text { Berat biji jagung } \\
(\mathbf{K g})\end{array}$ & $\begin{array}{c}\text { Berat biji jagung } \\
\text { keluar dari drum } \\
(\mathbf{k g})\end{array}$ & $\begin{array}{c}\text { Berat biji jagung } \\
\text { menempel dalam drum } \\
\mathbf{( k g )}\end{array}$ & $\begin{array}{c}\text { Kehilangan } \\
(\%)\end{array}$ \\
\hline I & 50 & 0,1 & 0,3 & 0,8 \\
II & 50 & 0,1 & 0,5 & 1,2 \\
Rata-rata & 50 & 0,1 & 0,4 & 1,0 \\
\hline
\end{tabular}

\section{Uji mutu biji jagung}

Mutu jagung yang dihasilkan dianalisis berdasarkan Standar Mutu Jagung SNI 01-3920-1995. Hasil analisis diulang sebanyak 2 kali dengan berat jagung 50 $\mathrm{kg}$. Rata-rata hasil percobaan pada alat pengering jagung sistem rotary dapat dilihat pada Tabel 4. 
Tabel 4. Hasil Analisis Mutu Jagung

\begin{tabular}{llccccc}
\hline & & \multicolumn{3}{c}{ Persyaratan mutu SNI } & Hasil Percobaan \\
No. & & J & II & III & IV & \\
\hline 1 & Kadar air (\%) & Maks 14 & Maks 14 & Maks 15 & Maks 17 & 16,13 \\
2 & Butir rusak (\%) & Maks 2 & Maks 4 & Maks 6 & Maks 8 & 0,08 \\
3 & Butir warna lain (\%) & Maks 1 & Maks 3 & Maks 7 & Maks 10 & 0,02 \\
4 & Butir pecah (\%) & Mak 1 & Maks 2 & Maks 3 & Maks 3 & 0,00 \\
5 & Kotoran (\%) & Maks 1 & Maks 1 & Maks 2 & Maks 2 & 0,06 \\
\hline
\end{tabular}

Pada Tabel 4, menunjukkan bahwa biji jagung yang dihasilkan dengan menggunakan alat pengering rotary dengan dua kali ulangan menghasilkan kadar air rata-rata $16,13 \%$, masuk kategori mutu IV untuk standar mutu jagung tercantum dalam Standar Nasional Indonesia (SNI) Nomor 01-03920-1995.

\section{Kadar Air}

Pada Tabel 4, dapat dilihat perlakuan biji jagung kadar air awal 30,37\% dikeringkan selama 10 jam pada alat pengering rotary dihasilkan kadar air akhir 16,13\% dengan suhu pemanasan rata-rata $70-75 \%$. Perlu diketahui suhu pada drum pengering antara $70-75^{\circ} \mathrm{C}$ dapat ditingkatkan sampai dengan $90-95^{\circ} \mathrm{C}$. Untuk penyetelan suhu pada alat pengering dapat dilakukan sesuai keinginan tergantung produk apa yang akan di keringkan. Mesin pengering biji jagung dapat digunakan setiap saat dan dapat dilakukan pengaturan suhu sesuai dengan kadar air biji jagung yang diinginkan.
Pada Gambar 4 di atas, bahwa penggunaan temperatur pengeringan kisaran $70^{\circ} 75^{\circ} \mathrm{C}$ maka proses pengeringan semakin meningkat. Hal tersebut dikarenakan makin tinggi suhu udara pengering maka makin tinggi energi panas yang dibawa udara sehingga makin banyak jumlah massa cairan yang diuapkan dari permukaan bahan. Dengan adanya kenaikan suhu maka akan menaikkan suhu bahan dan menyebabkan tekanan uap air di dalam bahan lebih tinggi daripada tekanan uap air di udara, sehingga terjadi perpindahan uap air dari bahan ke udara (9).

Pada Gambar 4, juga menunjukkan bahwa kadar air yang dicapai rendah sehingga air yang tertinggal dan terikat secara kimia semakin sulit diuapkan akibatnya penurunan kadar air semakin kecil dan semakin sulitnya pergerakan air dari pusat menuju permukaan bahan. 


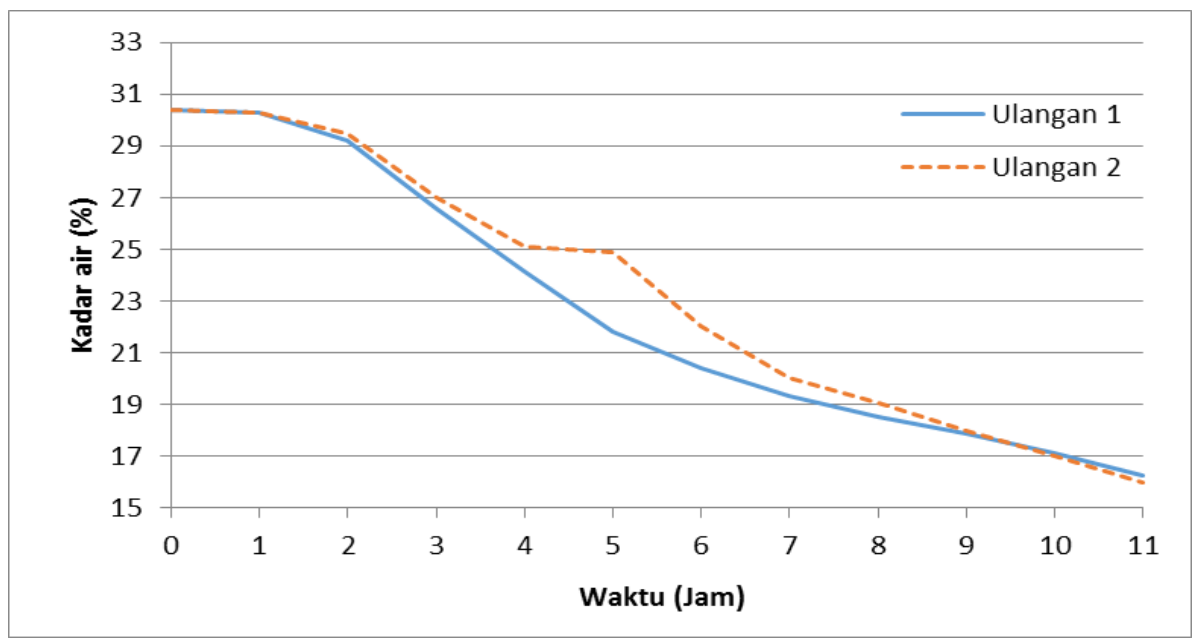

Gambar 4. Penurunan kadar air dengan waktu pengeringan

Dalam mekanisme pengeringan untuk bijibijian, proses perpindahan panas terjadi karena suhu bahan lebih rendah dari pada suhu udara yang dialirkan di sekelilingnya. Panas yang diberikan ini akan menaikkan suhu bahan yang menyebabkan tekanan uap air di dalam bahan lebih tinggi dari pada tekanan uap air di udara, sehingga terjadi perpindahan uap air dari bahan ke udara yang merupakan perpindahan massa (10). Sebelum proses pengeringan berlangsung, tekanan uap air di dalam bahan berada dalam keseimbangan dengan tekanan uap air di udara sekitarnya. Pada saat pengeringan dimulai, uap panas yang dialirkan meliputi permukaan bahan akan menaikkan tekanan uap air, terutama pada daerah permukaan, sejalan dengan kenaikan suhunya. Pada saat proses ini terjadi, perpindahan massa dari bahan ke udara dalam bentuk uap air berlangsung atau terjadi pengeringan pada permukaan bahan. Setelah itu tekanan uap air pada permukaan bahan akan menurun. Setelah kenaikan suhu terjadi pada seluruh bagian bahan, maka terjadi pergerakan air secara difusi dari bahan ke permukaannya dan seterusnya proses penguapan pada permukaan bahan diulang lagi. Akhirnya setelah air bahan berkurang, tekanan uap air bahan akan menurun sampai terjadi keseimbangan dengan udara sekitarnya. (6).

Pola penurunan kadar air selama proses pengeringan berlangsung seragam (lihat Tabel 4 dan Gambar 4), hal ini disebabkan karena kadar air dan kecepatan pengeringan tidak terdapat perbedaan baik kondisi maupun suhu selama proses pengeringan maupun udara lingkungan sekitarnya. Suhu ruang pengering dipengaruhi oleh stabilitas pengumpanan bahan bakar, sedangkan bahan bakar yang diumpankan dipengaruhi oleh kondisi udara lingkungan dan oleh bahan yang dikeringkan (11).

2. Butir Rusak

Pada Tabel 4, dapat dilihat bahwa persentase kerusakan hasil biji jagung pada alat pengering rotary sekitar $0,08 \%$. Kerusakan hasil yang diperoleh $0,08 \%$ bila dibandingkan dengan pengolahan petani (perontokan dan pemipilan) dengan tingkat kehilangan hasil mencapai 4-8\%, (11). Kerusakan hasil tidak terjadi pada alat pengering rotary yang di rekayasa, kemungkinan hanya terikut/terbawa dalam pengadaan/pembelian bahan baku biji jagung (12).

Hasil percobaan pada alat pengering rotary menunjukkan bahwa biji jagung rusak masih 
dibawah $2,0 \%$ yaitu $0,08 \%$, hal ini sudah sesuai dengan SNI jagung. Tinggi rendahnya persentase kerusakan hasil biji jagung digolongkan sebagai akibat perlakuan mekanis atau fisik selama proses pengeringan.

\section{Butir warna lain}

Pada Tabel 4, dapat dilihat bahwa persentase butir warna lain hasil biji jagung pada alat pengering rotary sekitar $0,02 \%$. Hasil percobaan pada alat pengering rotary menunjukkan bahwa biji jagung rusak masih dibawah $2,0 \%$ yaitu $0,02 \%$, sudah memenuhi syarat SNI untuk mutu I sampai mutu IV. Hasil persentase butir warna lain $0,02 \%$ (warna kuning dan semua sama) sudah memenuhi syarat SNI, hal ini menunjukan bahwa varietas yang didapat semua warna asli (kuning).

\section{Butir pecah}

Pada Tabel 4, dapat dilihat bahwa persentase butir pecah hasil biji jagung pada alat pengering rotary sekitar $0 \%$. Hasil percobaan pada alat pengering rotary menunjukkan bahwa biji jagung parameter butir pecah masih dibawah $1,0 \%$ yaitu $0,00 \%$, hal ini sudah sesuai dengan $\mathrm{SNI}$ jagung. Tinggi rendahnya butiran pecah pada jagung sebagai akibat perlakuan mekanis atau fisik selama proses pemipilan, dimana biji pecah-pecah (rpm yang tinggi 900 rpm). Persentase butir pecah adalah $0 \%$ (tidak mengalami pecah) hal ini menunjukkan bahwa jagung hasil proses pengeringan tidak ada yang pecah.

\section{Kotoran}

Pada Tabel 4, dapat dilihat bahwa persentase kotoran hasil biji jagung pada alat pengering rotary sekitar $0,06 \%$. Bila dibandingkan dengan pengolahan petani (perontokan dan pemipilan) dengan tingkat kehilangan hasil mencapai 4-8\% (11). Kerusakan hasil tidak terjadi pada alat pengering rotary yang direkayasa, kemungkinan hanya terikut/terbawa dalam pengadaan/pembelian bahan baku biji jagung.

Hasil percobaan pada alat pengering rotary menunjukkan bahwa biji jagung rusak masih dibawah $2,0 \%$ yaitu $0,06 \%$ hal ini sudah sesuai dengan SNI jagung. Rendahnya Persentase kotoran selama pengering dapat diketahui dengan segala benda asing seperti : butir tanah, batu-batu kecil pasir dan sisa-sisa batang, tongkol jagung dan bijian lain yang bukan jagung (8). Hasil kotoran dapat dicegah jika bahan baku di sortasi dengan teliti dengan seksama sebelum dimasukkan ke dalam drum pengering.

\section{KESIMPULAN}

Kegiatan rancangan alat pengering system "rotary dryer" telah dilakukan dengan spesifikasi berbentuk silinder drum pengering dengan dimensi panjang $220 \mathrm{~cm}$ lebar $62 \mathrm{~cm}$ dan tinggi $50 \mathrm{~cm}$ dilengkapi drum penampung, termometer, motor listrik $1 \mathrm{HP} / 1420 \mathrm{rpm}$, reducer, dan bahan bakar gas LPG.

Hasil pengamatan alat pengering jagung hasil percobaan pada kapasitas $50 \mathrm{~kg}$ jagung dengan waktu pengering selama 10 jam dengan kadar air awal 30,37\% menjadi kadar air akhir $16,13 \%$ jagung kering, suhu rata-rata $70-75^{\circ} \mathrm{C}$ dengan bahan bakar gas LPG.

Kemampuan kinerja pada percobaan alat mesin pengering jagung system rotary adalah kadar air 16,13\%, kehilangan hasil 1,0\%, rendemen $82 \%$. Sedangkan hasil pengamatan mutu dari uji coba alat pengering jagung adalah kadar air $16,13 \%$, butir rusak $0,02 \%$, butir pecah $0,02 \%$ dan kotoran $0,06 \%$. Hal ini sudah memenuhi syarat mutu jagung Standar Nasional Indonesia (SNI) Nomor : 01-39201995. 


\section{DAFTAR PUSTAKA}

1. Earle RL. Satuan operasi dalam pengolahan pangan. Penerjemah Nasution Z. Bogor: Sastra Hudaya; 1999.

2. Taib G, Sa'id EG, Wiraatmaja S. Operasi pengeringan pada pengolahan hasil pertanian. Jakarta: Mediyatama Sarana Perkasa; 1988.

3. Sumarsono. Kajian perilaku suhu udara dalam ruang pengering. Jurnal Penelitian UNIB. Vol. X. 2004. No.1, HIm. 20-25.

4. Johannes, $\mathrm{H}$. Flower pot and brick pit stove burning rice hull. Jogyakarta: Fine Leaves and Coarce Biomass, Regional Seminar on Solar drying. 1984

5. Jumari A dan Purwanto A. Design of rotary dryer for improving the quality of product of semi organic phospate fertilizer. Jurusan Teknik Kimia F.T. UNS: Solo; 2005.

6. Susilo I. Persiapan bahan tanam pada tanaman jagung. Fakultas Pertanian Muhammadiyah. Jogyakarta; 2013.

7. Suma SD. 2009. Teknologi pasca panen untuk peningkatan mutu jagung. Teknik Teknologi Industri Kecil Menengah. Fakultas Teknik Universitas Gadjah Mada. Jogyakarta; 2009.

8. Subekti D. Pengembangan alat pengering jagung mekanis model sumur untuk tingkat pedesaan. Fateta IPB, Bogor; 1986.

9. Wikan, dkk. Uji kinerja mesin pengering biji kakao tipe plenium ganda dengan pemanasan tidak langsung. Buletin enjiniring Pertanian, Vol 2, No. 2. Balai Besar Pengembangan Alat \& Mesin Pertanian. Serpong; 1995.
10. Anonim.. Rotary Dryer, 2009. http://www.artech.co.id, diakses 11 Juni 2016.

11. Lahming. Rancang bangun alat pengering bijibijian hasil pertanian tipe kontinu bahan bakar biomassa ramah lingkungan. Jurusan Teknik Mesin Universitas Negeri Makasar; 2012.

12. Sitompul JP, Istadi NS, Nugroho dan Aghista R. Studi eksperimental pengeringan butiran jagung dalam pengering unggun diam. Jurusan Teknik Kimia, Institut Teknologi Bandung; 2008. 